\title{
Energia do Hidrogênio e a Área de Materiais no Brasil
}

Paulo Emílio V. de Miranda ${ }^{1}$

\author{
${ }^{1}$ Editor-Chefe \\ Universidade Federal do Rio de Janeiro - UFRJ, Laboratório de Hidrogênio - LabH2-COPPE, Av. Moniz \\ Aragão, 207, 21941-594, Rio de Janeiro, RJ, Brasil. \\ E-mail: pmiranda@coppe.ufrj.br
}

A emergência ambiental que o planeta já vivia tornou-se mais impactante com os efeitos devastadores da pandemia de Covid-19 em larga escala em todo o mundo e, em particular, e de forma socialmente lamentável no Brasil. Ficou, assim, mais evidente a necessidade pela adoção de tecnologias sustentáveis em todos os setores. Isso enfatizou a busca por formas não poluentes de produção e uso de energia, com preferência pelas energias renováveis e pela energia do hidrogênio. O decréscimo ou mesmo a eliminação da geração de gases de efeito estufa, de hidrocarbonetos resultantes da combustão de combustíveis fósseis e de materiais particulados, principalmente, em ambientes urbanos, diminui também o impacto em doenças respiratórias e cardíacas [1], que criam comorbidades capazes de gerar sinergia deletéria com a Covid-19. Com isso, o emprego de tecnologias para o uso do hidrogênio e pilhas a combustível [2] ganharam forte evidência.

No início do ano de 2021 mais de 30 países publicaram roteiros para energia do hidrogênio, a indústria anunciou mais de 200 projetos sobre hidrogênio e pilhas a combustível, com planos de investimento ambiciosos e foram anunciadas ações de diversos governos relativo ao investimento de mais de 70 bilhões de dólares com verba pública [3]. Além disso, mais de 20 países expressaram a intenção de banir o uso de veículos com motores a combustão interna antes de 2035 e foi identificado que a paridade de custo de veículos pesados a diesel com aqueles portando motorização elétrica com hidrogênio e pilhas a combustível, ocorrerá entre 2025 e 2028. Pequenos e grandes centros urbanos criaram regulamentos para transporte sustentável, como foi os casos de Maricá, RJ, [4] e o município do Rio de Janeiro [5].

Neste último, o serviço de transporte público coletivo de passageiros realizado por ônibus a partir de $1^{\circ}$ de janeiro de 2025 somente poderá ser celebrado sob a previsão contratual de utilização de ônibus de emissão zero. Ademais, começaram também a ser experimentados procedimentos que passaram por longos anos de desenvolvimento científico e que agora começam a encontrar aplicações práticas em larga escala que realizam a captura e o sequestro de $\mathrm{CO}_{2}$ do ar [6].

Esse novo panorama abriu enormes possibilidades de desenvolvimento científico e de demonstração tecnológica para a área de materiais. Isso porque são requeridos novos materiais de todas as categorias e, principalmente, materiais nanoesruturados, materiais compósitos, novos materiais metálicos, polímeros condutores iônicos, cerâmicos condutores mistos e filmes com propriedades eletrocatalíticas.

\section{BIBLIOGRAFIA}

[1] MIRANDA, P. E. V., "Materiais Particulados: Produtos Ameaçadores Resultantes da Queima de Combustíveis", Matéria, v. 18, n. 4, 2013.

[2] MIRANDA, P. E. V., Editor, "Science and Engineering of Hydrogen-Based Energy Technologies", $1^{\text {st }}$ Edition, ELSEVIER, Academic Press, 438 p, 2019.

[3] HYDROGEN COUNCIL, "Hydrogen Insights - A perspective on hydrogen investment, market development and cost competitiveness", 2021.

[4] Lei No 2.871, de 19 de junho de 2019, Maricá, Rio de Janeiro, RJ.

[5] Decreto Rio No 46081, de 11 de junho de 2019, Rio de Janeiro, RJ. 
[6] REALMONTE, G., DROUET, L., GAMBHIR, A., et al.,

"An inter-model assessment of the role of direct air capture in deep mitigation pathways", Nature Communications, Disponível em: https://doi.org/10.1038/s41467-019-10842-5, 2019.

\section{ORCID}

Paulo Emílio V. de Miranda

https://orcid.org/0000-0002-8968-3308 